CAPÍTULO I ORIGEN DE RADIO SUTATENZA Y ACCIÓN CULTURAL POPULAR

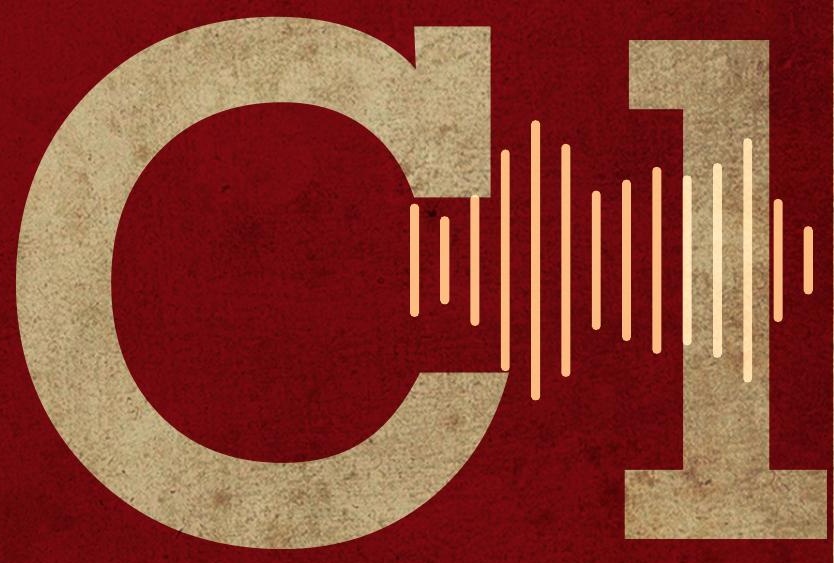




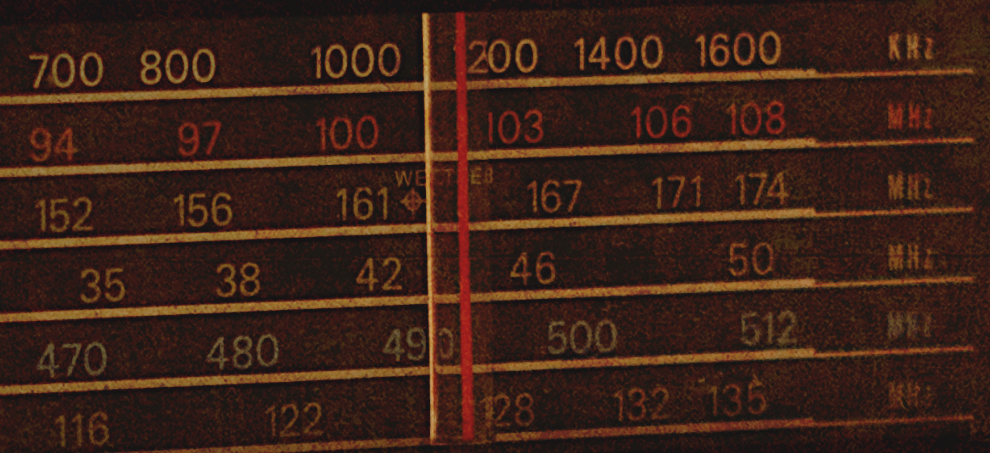

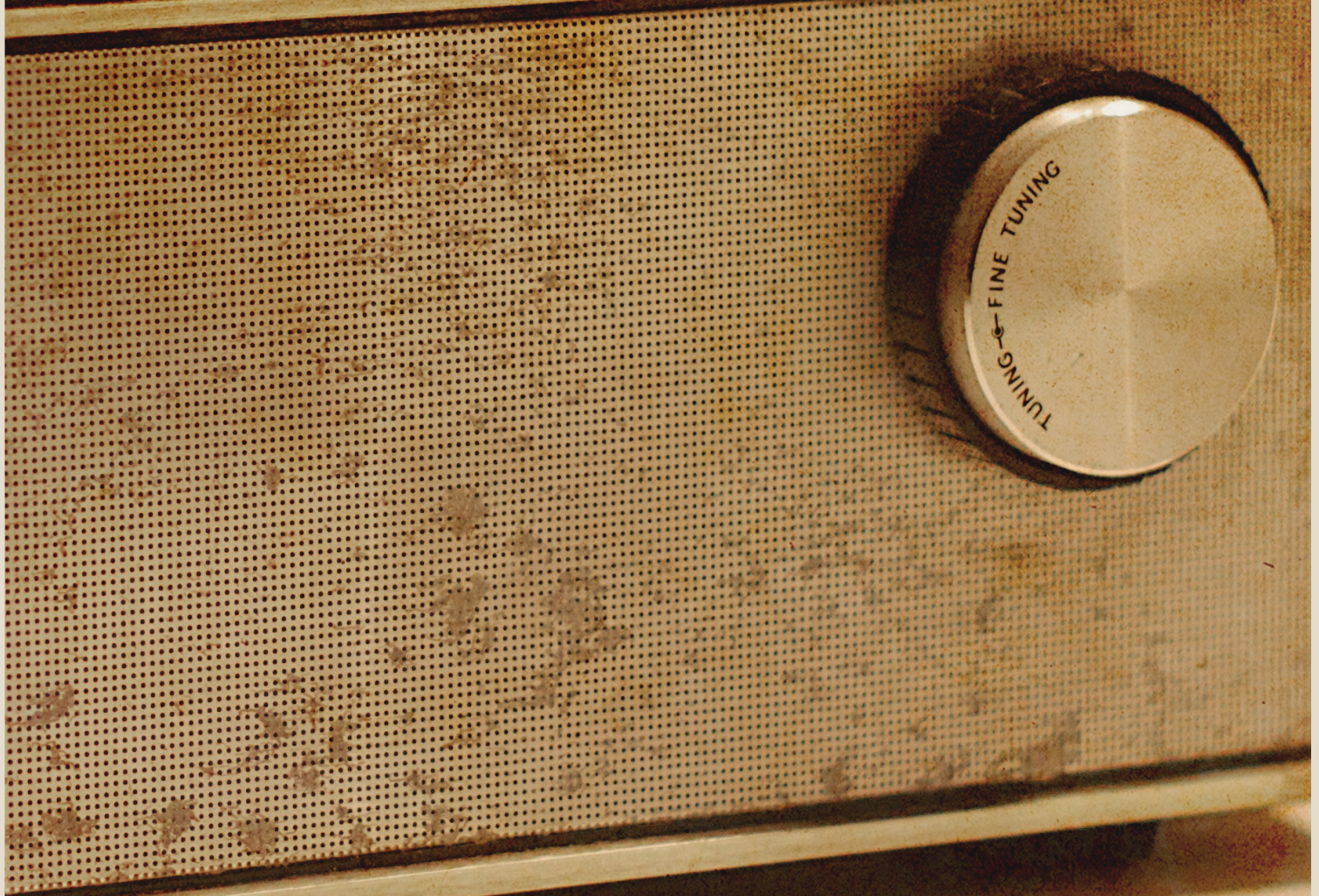




\section{ORIGEN DE RADIO SUTATENZA Y ACCIÓN CULTURAL POPULAR}

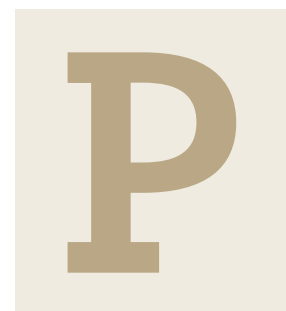
Popular y el trabajo que desarrolló en la institución. Además, deja entrever las relaciones de Salcedo con los políticos del país, con organizaciones internacionales y con la misma Iglesia, en el marco de creación y consolidación de Acción Cultural Popular.

Radio Sutatenza empieza a funcionar bajo un contexto particular que permitió llevar a cabo la novedosa propuesta educativa a través de medios de educación. Las características de ese contexto se enmarcaban en una fuerte presencia de la religión católica en el país, una situación de violencia permanente y el desarrollo de un medio de comunicación como la radio, que había empezado a hacer presencia en Colombia en 1930.

Este capítulo muestra cuál es el origen del proyecto del padre José Joaquín Salcedo, quien utilizó la radio como un medio para la educación campesina en Colombia. Este proyecto se inició en el municipio de Sutatenza, en el departamento de Boyacá, y precisamente de allí adquirió su nombre la emisora que cubrió con su señal buena parte del país. Esta fue un componente de la institución que se creó dos años más tarde, denominada Acción Cultural Popular. 


\section{Caracterización de la población campesina}

Radio Sutatenza empieza a funcionar en 1947, en momentos en que la violencia partidista se presentaba en el país, la pobreza del campesinado era evidente y la clase obrera trabajadora venía creciendo en las ciudades, manifestando su inconformismo por la situación laboral. A partir de los trabajos realizados por sociólogos como Gustavo Pérez y Orlando Fals Borda se hará a continuación una caracterización del campesino colombiano y, en particular, en algunos casos, de los habitantes de las zonas rurales de Boyacá y de la región del Valle de Tenza, precisamente donde se encuentra el municipio de Sutatenza. Allí fue donde inició labores Radio Sutatenza con sus Escuelas Radiofónicas.

El Valle de Tenza es una inmensa depresión formada por los ríos Súnuba y Garagoa, y se subdivide en veredas, como la mayoría de las regiones del país. Dentro de los municipios, estas veredas eran confiadas a un comisario o a un inspector que velaba por el orden en ese territorio. En esta región se encuentra el municipio de Sutatenza, que está ubicado a cinco minutos de Guateque, la capital de la provincia de Oriente Boyacense, que a principios de la década de los años de 1950 contaba con no más de 3.000 habitantes y basaba su economía en la agricultura, las explotaciones pecuarias y la minería.

En los primeros años de Radio Sutatenza, la población colombiana se caracterizaba por habitar mayoritariamente en las zonas rurales y ejercía actividades agrícolas. Para 1951, según el estudio realizado por Gustavo Pérez, el 55,6\% de la población colombiana vivía en caseríos o sitios distantes a las cabeceras municipales. Es decir, más de la mitad de la población colombiana se dedicaba a labores agrícolas.

Debido a la dispersión de las zonas habitacionales, en Boyacá se concentraba sólo el 13,64\% de la población del país. ${ }^{6}$ La falta de medios y vías de comunicación llevó a que las diferentes zonas del país estuvieran aisladas. A pesar de que gran parte de los colombianos habitaba la región Andina (78,4\%), las posibilidades de relación e integración eran muy difíciles. Estas cifras coinciden con la densidad poblacional observada en poblados pertenecientes al Valle de Tenza como Guayatá, que tenía 171 habitantes por kilómetro cuadrado, Guateque 244, Tenza 256 y Sutatenza 98,5 habitantes, siendo el Valle de Tenza el sector de Boyacá con mayor densidad poblacional? .

6. PÉREZ, Gustavo. El Campesinado Colombiano, un problema de estructura. Bogotá, Editorial Iqueima, 1959. p. 39

7. FALS, Orlando. El Hombre y la Tierra en Boyacá, 4ta ed., Tunja, UPTC, 2006, p.244 
El crecimiento de la densidad poblacional se encontraba para el año de 1954 en un $2,2 \%$. A pesar de no ser demasiado alto, este comprometía el nivel de empleos e ingresos de la población, empeorando las condiciones de vida de los colombianos. Para la década de los años de 1950, en el país las familias estaban compuestas por 5,7\% miembros. En Boyacá, de acuerdo con el estudio Estructuras demográficas y sociales de Colombia, las familias eran de aproximadamente cuatro personas ${ }^{8}$. En esta cifra coincide Orlando Fals Borda en la investigación desarrollada sobre los Campesinos de los Andes?. El número de miembros por familia era alto, de acuerdo con los niveles de ingresos obtenidos por los habitantes del departamento, especialmente en el sector rural.

Gustavo Pérez afirma: "la sobreoferta de la mano de obra provoca un estado de subempleo, de empleo simulado, que entraña un despilfarro de las fuerzas de trabajo y un empleo abusivo de la mano de obra", que por supuesto implicaba una disminución en los salarios de los campesinos.

Específicamente en Boyacá, los ingresos entre 1950 y 1954, según el Anuario General de Estadística, fueron para los hombres de 2,41 pesos y para las mujeres de 1,74 pesos. Estos salarios eran unos de los más bajos del país, estando solo por debajo los del departamento del Atlántico y de Nariño. El más alto correspondía al departamento del Tolima, con 4,03 pesos para los hombres y 2,43 pesos para las mujeres. Pérez evidencia que en aquellas zonas donde los salarios eran menores, también era donde se presentaba mayor presencia de la mujer trabajadora. Sin embargo, el porcentaje nacional fue realmente bajo, alcanzando solo el 4,5\%. Las condiciones laborales de las mujeres eran aún más precarias que la de los hombres.

Esta situación se vio agravada por la falta de formación de la población campesina. Pérez evidencia que los niños y niñas del campo escasamente alcanzaban a cursar entre el primer y segundo grado de primaria, para posteriormente retirarse de las aulas y dedicarse a las labores agrícolas junto con sus padres.

Como se comentó inicialmente, las familias campesinas, por lo general, vivían aisladas y desconfiaban de toda organización. Las condiciones sociológicas del campesino colombiano, según Pérez, llevaron a que se caracterizara por ser un individuo fundamentalmente individualista. Esta situación permitió que

8. DE LANNOY, Juan y PÉREZ, Gustavo. Estructuras demográficas y sociales en Colombia. Bogotá, Centro de Investigaciones Sociales, p. 158

9. FALS, Orlando. Campesinos de los Andes. Bogotá, Universidad Nacional, 1961. p. 242. 
se mantuvieran las discriminaciones y los bajos salarios. El aislamiento del campesinado, escasamente se veía interrumpido cuando acudía, como comenta Fals Borda, a la iglesia, al mercado o a las tiendas, que eran los puntos de encuentro de las comunidades. ${ }^{10}$

Se puede observar que las zonas del país donde se cultivaban productos como el café ofrecían un mayor ingreso a los campesinos. Igualmente, esas zonas tenían unas migraciones constantes, mientras que las zonas dedicadas más al cultivo de productos de autoconsumo no recibían mayor cantidad de población de otros departamentos. Boyacá fue, en este sentido, una de las zonas que mantenía gran población autóctona, el 96,7\% de los habitantes eran agricultores de la misma región"1. Al respecto, Orlando Fals Borda menciona que "esta tremenda exclusividad

del boyacense ha sido tradicional. Es un hecho al cual se le debe brindar gran significado sociológico: al cerrar sus puertas a los que llevan culturas foráneas, Boyacá, así como hasta cierto punto Colombia toda, ha mantenido una civilización provinciana que en muchos aspectos ha quedado rezagada"12.

Las precarias condiciones económicas del campesino y el pobre poder adquisitivo producían deficiencias en la alimentación, en las condiciones de la salud, de la cultura y del trabajo. Las carencias en diferentes aspectos condicionaban los rendimientos en el trabajo; entre menor era la calidad de vida, también eran menores las posibilidades de hacer un buen trabajo. Era un círculo que mantenía al campesino con pocas posibilidades de mejorar su situación.

Gustavo Pérez, en su investigación caracterizó también las condiciones de las casas rurales; en este sentido determinó que las estructuras habitacionales contaban, en general, con una sola alcoba de una superficie de 4 metros cuadrados. Las casas tenían unos 20 metros cuadrados y eran construidas en adobe, tierra pisada, guadua o bahareque. Los techos eran de paja o de madera. “En general, la casa campesina carece de muebles. No hay armarios, sino baúles o cajas que sirven al mismo tiempo de asientos"13. Pérez agrega que es notoria la falta de iluminación y además que se duerme con la ropa

10. FALS, Orlando. El Hombre y la Tierra ... p. 201.

11. La fuente utilizada por Pérez fue el Censo de 1951, donde discrimina la población por lugar de nacimiento, actividad económica y sexo.

12. FALS, Orlando. El Hombre y la Tierra... p.44

13. PÉREZ, Gustavo. El Campesinado Colombiano... p. 110 
de trabajo, ya sea en hamacas o bancos que sirven de cama. Adicionalmente, carecían de servicios higiénicos, agua potable y electricidad. ${ }^{14}$

En cuanto a la alimentación, el estudio determinó que el campesino colombiano consumía suficientes calorías, pero era deficiente en proteínas, grasas, calcio, fósforo y vitamina A. En zonas frías como las de Boyacá, el consumo generalmente era de papa, habas, maíz y trigo. El consumo de carne a nivel nacional era significativamente bajo, llegando a entre 20 y $25 \mathrm{~kg}$. por persona. Según el análisis desarrollado por Gustavo Pérez, la falta de vías de acceso y de transporte adecuado fue una de las causas de la baja producción nacional de alimentos: "No es exagerado ver en este estado de subalimentación y de mala nutrición del pueblo un factor poderoso que contribuye a la deficiencia de la agricultura y especialmente al bajo nivel de rendimiento del trabajador"15.

Una de las características del departamento de Boyacá es que la forma predominante de la tenencia de la tierra era la de propietario con un $77 \%$. Sin embargo, esas extensiones territoriales no eran sino pequeñas propiedades. Específicamente en el municipio de Sutatenza, de un total de 1.588 viviendas, el $86 \%$ estaban habitadas por sus propietarios, mientras que el $10,1 \%$ por arrendatarios. El restante $3,8 \%$ correspondía a otras formas u otros usos. Aunque los minifundios se encuentran en casi todo el departamento de Boyacá, sobresale el Valle de Tenza. "Sutatenza, con una densidad de 98,5 habitantes, es un buen ejemplo de un área de minifundios... Es difícil comprender cómo sobreviven estos agricultores: solo parece que la tierra diera cosechas suficientes como para compensar la falta de espacio. Pero en cambio queda en evidencia por qué los tenzanos son pobres desde varios puntos de vista"16.

Una de las áreas trabajadas por Acción Cultural Popular era la educación, pues consideraba que la situación del campesinado era uno de los grandes problemas nacionales. El porcentaje de analfabetos, de acuerdo con lo mencionado por Pérez, llegaba a 42,4\%. El autor afirma que el analfabetismo en las zonas rurales obedecía a causas socioeconómicas e históricas. En general, los niños campesinos colaboraban en las labores de la cosecha y las niñas en los quehaceres del hogar, por lo que su asistencia a clase no era continua. Fals Borda resalta que en Boyacá

14. En relaciones con las condiciones habitacionales, Orlando Fals Borda, en el libro El hombre y la Tierra en Boyacá, confirma las características descritas por Gustavo Pérez en cuanto a los materiales usados para su construcción, y los implementos adquiridos y utilizados dentro de las casas.

15. PÉREZ, Gustavo. El Campesinado Colombiano... p. 118.

16. FALS, Orlando. El Hombre y la Tierra... p. 162 
los niveles de analfabetismo son más altos y alcanzan una cifra del $54,4 \%$, uno de los porcentajes más altos del país ${ }^{17}$.

El estudio de Pérez hace mención de la labor cumplida por Acción Cultural Popular. En lo referente a la educación rural colombiana, destaca el papel de las Escuelas Radiofónicas de Sutatenza. "Con muy buena organización y técnica y un sentido patriótico descollante, estas Escuelas buscan llegar al campesino en su aislamiento. No solo tratan de alfabetizarlo, sino de darle cultura general con pautas para el laboreo de la tierra, el mejoramiento del hogar y la elevación de su estándar de vida"18.

Tres años después de la publicación del trabajo El Campesino Colombiano, un problema de estructura, Gustavo Pérez, junto con Juan Luis de Lannoy, publicó la investigación sociológica titulada Estructuras demográficas y sociales de Colombia, donde analiza la población colombiana desde diferentes aspectos como su movilidad, su distribución étnica, el aumento en las tasas de crecimiento y la composición de la población. De igual manera, hace un balance y análisis de la evolución, situación y localización de los diferentes grupos sociales del país.

Tal y como se evidenció en la investigación sobre el campesinado colombiano, el crecimiento de la población siguió siendo una preocupación, pues alcanzaba porcentajes hasta del 2,9\%, lo que preveía que en 23 años se duplicara la población del país. Estos niveles de crecimiento poblacional debían ir de la mano de un aumento proporcional en la producción agrícola e industrial que garantizara elevar la calidad de vida.

Del mismo modo, en lo relacionado con la distribución demográfica percibió una dispersión geográfica que tenía como consecuencia desigualdades entre diferentes zonas del país. Desigualdades que se veían reflejadas en los índices de mortalidad infantil, en la natalidad, en el nivel de vida y en la producción económica. Desde esta mirada, el planteamiento de la implementación de una reforma agraria era urgente para los autores. Orlando Fals Borda, en su trabajo El hombre y la Tierra en Boyacá, también señala que la meta principal de la reforma agraria debía ser "el bienestar socio económico que viene con el aumento parsimonioso de la producción, y la superación física y cultural del hombre del campo como elemento indispensable para la prosperidad nacional"19.

17. Ibid., p.48.

18. PÉREZ, Gustavo. El Campesinado Colombiano...pp. 124 y 125.

19. FALS, Orlando. El Hombre y la Tierra... p.235. 
Otra preocupación tenía que ver con las migraciones del campo a la ciudad: el desplazamiento de mujeres, jóvenes y niños a las ciudades ocasionaría nuevos problemas, pues la población económicamente activa de los sectores primarios disminuiría mientras los sectores secundarios y terciarios contarían con mayor mano de obra.

El papel que jugó la Iglesia Católica en ese contexto abarcó el ámbito político, el educativo y el social. De una parte, la lucha política no le era ajena, la Iglesia siempre se mantuvo en relación con el poder y en ese sentido había tomado partido a favor o en contra en muchas ocasiones. Generalmente tuvo coincidencias ideológicas con el partido conservador y contradicciones con el partido liberal. Con este último mantuvo una confrontación mayor cuando el presidente López Pumarejo intentó impulsar un Estado laico, donde existiera separación entre el Estado y la Iglesia, pero con espacios de colaboración entre los dos poderes. Por ejemplo, la Iglesia seguía dirigiendo varios colegios católicos y seguía manteniendo el control sobre el estado civil y la soberanía sobre los territorios donde la Iglesia llevaba a cabo misiones. López, en este sentido, buscó la colaboración del clero con el Estado “ayudándolo a elevar el nivel intelectual y material del pueblo"20. Si bien se quería tener un Estado laico, también se quería mantener la cooperación entre el Estado y la Iglesia.

La educación fue otro escenario donde tuvo presencia la Iglesia Católica. Administraba los centros de educación, donde las enseñanzas incluían una fuerte formación católica. También, mediante proyectos de carácter social, la Iglesia evangelizó e intentó realizar labores que mejoraran las condiciones de vida de los colombianos. Las acciones en este sentido constituyeron, entre otras, la organización de la Juventud Obrera Católica (JOC), en 1933, la organización de sindicatos católicos, las cooperativas locales y el apoyo a asociaciones de caridad.

Durante este periodo, el país se caracterizó por la creciente confrontación partidista que llevó a que los enfrentamientos entre liberales y conservadores se intensificaran. Una de las regiones donde era evidente dicha situación fue precisamente en el departamento de Boyacá, donde José Joaquín Salcedo nació, creció y se formó como sacerdote. El fundador de Radio Sutatenza nació en la población de Corrales, un municipio agrícola de estirpe conservadora donde habitaban sus padres, José Joaquín Salcedo Cujar y Eva María Perry de Salcedo.

20. ARIAS, Ricardo. Episcopado Colombiano: Intransigencia y laicidad (1850 - 2000), Bogotá, Uniandes, 2003 p. 128 
En 1920, un año antes del nacimiento de Salcedo, los cables del telégrafo se empezaron a levantar en este municipio, mejorando así la comunicación entre los habitantes de Boyacá y el sur del país. La administración de los telégrafos en el municipio de Corrales estuvo a cargo de José Joaquín Salcedo Cujar, lo que permitió que su hijo tuviera un constante acercamiento a dicha tecnología y en general a las telecomunicaciones. Al lado de su padre, Salcedo aprendió telegrafía trabajando en la oficina repetidora entre Bogotá, Sogamoso y los Llanos del Casanare.

Sin embargo, este no fue el único adelanto tecnológico que conoció Salcedo en Corrales: hacia 1930 la radio llegó al municipio. Quienes instalaron los equipos se alojaron en la casa de los Salcedo y tenían la misión de ubicar la enorme antena en la Casa Consistorial, e instalar el mueble receptor y los altoparlantes en diferentes lugares de la plaza para que el público escuchara lo que se transmitía ${ }^{21}$.

\section{Antecedentes de la radio}

Los antecedentes de la radio en Colombia datan de los primeros años del siglo XX, especialmente lo que tiene que ver con la puesta en marcha de la Radiodifusora Nacional de Colombia, que oficialmente se inauguró durante el gobierno de Eduardo Santos. ${ }^{22}$ Sin embargo, es importante precisar que la radio como tecnología de información ya había empezado a operar en 1929, cuando el país estaba en el conflicto limítrofe con el Perú. Para ese momento, Miguel Abadía Méndez inauguró la estación de radio HJN que sirvió para “comunicar órdenes militares y para informar a la opinión nacional acerca del desarrollo del conflicto" ${ }^{23}$.

Renán Silva, en el texto República Liberal, Intelectuales y Cultura Popular, plantea que en la primera etapa de la radio en Colombia, es decir, desde la creación de HJN hasta 1946, esta se utilizó como un medio donde estaba presente una idea de "nación de identidad colectiva, de interés general y público" ${ }^{24}$, dentro de una concepción de libertad de información y de creación intelectual. De esta manera,

21. ZALAMEA, Luis. El Quijote Visionario, Bogotá, Jorge Plazas Editor, 1994

22. GÓMEZ, Gabriel y QUINTERO, Juan. Diagnóstico del servicio de radiodifusión de interés público, Bogotá, Ministerio de Comunicaciones, 2003, p. 12

23. SILVA, Renán. Ondas nacionales. La política cultural de la república liberal y la radiodifusora nacional de Colombia. Revista Análisis Político, No. 41, p. 13

24. SILVA, Renán. República Liberal, Intelectuales y Cultura Popular, Medellín, La Carreta Editores, 2005, p. 64. 
la idea planteada hacía parte de la formación de un concepto de cultura que estaba constituida por la construcción de una identidad como nación.

Entonces, la radio no solamente se constituyó como un medio de información, sino como un proyecto cultural al que se le dio un carácter "social" a partir de la reforma constitucional de 1936. Esta identificación con lo social permitió caracterizar la radio como cercana a las políticas populares y a favor del pueblo que defendía el liberalismo, en contraposición a las políticas de élite que privilegiaban los conservadores según sus contradictores. Planteado de esta manera, "en el campo de la cultura, 'social' quería decir con toda precisión que se consideraba la cultura como una fuerza 'activa' y que en la educación popular se encontraba una condición de despegue económico" 25 . Renán Silva complementa que el término "social" también era entendido como el derecho que tenían los ciudadanos de participar y de disfrutar de los bienes culturales de la nación.

De esta manera, la cultura estaba asociada a un proceso educativo que tenía la posibilidad de ser extendido a través de los nuevos medios de comunicación como eran en su momento el cine y la radio. El ministro de educación encargado, Luis López de Mesa, planteó en 1931 que estos dos medios eran unos recursos educativos que podían desplazar los tradicionales métodos de la educación, y que por eso era urgente la necesidad de adaptarse y entender esas novedades e igualmente aprovechar las oportunidades que ofrecían. ${ }^{26}$ Es decir, estos medios podrían ser utilizados dentro de una política cultural como instrumentos que sirvieran para la alfabetización en diversas y remotas regiones.

Por medio del proyecto liberal de Cultura Aldeana, entre 1935 y 1936 se intentó divulgar expresiones de cultura intelectual en las sociedades campesinas. La intención fue mejorar los niveles de lectura y de vida, y aplicar conocimientos técnicos en actividades funcionales en su entorno, pero también favorecer la construcción de una forma coherente y homogénea de vida social, es decir que culturalmente hablando se conformara una comunidad y una nación. Este proyecto de Cultura Aldeana se convirtió así en una primera expresión de educación para los sectores rurales, a partir del uso de medios diferentes a los que habitualmente la Iglesia estaba acostumbrada a manejar en los diferentes centros de enseñanza que administraba.

25. Ibid., p. 67.

26. Ibid., p. 68. 
Posterior a la guerra con el Perú, el gobierno liberal intentó hacer de la radio un medio oficial de comunicación para la educación popular, "dotando a cada escuela pública de un radiorreceptor y un instrumento de integración nacional”27. Se pretendía que la radio se considerara como un servicio del Estado que tuviera como interés principal la divulgación de una programación cultural. Una radio que estuviera por encima de los intereses particulares y comerciales. Renán Silva señala que para Darío Echandía era de primer orden el uso de la radio y el cine como instrumentos para la creación de "una auténtica universidad popular a cuya enseñanza se acoja la totalidad de la población colombiana". Considera Silva que tanto Echandía como López de Mesa fueron dando las pautas para la creación del modelo de la radio cultural y educativa que se proponía el gobierno liberal. Lo que llamaba Echandía la universidad al aire era "el fomento del espíritu nacionalista, la vinculación entre las regiones, el servicio a la industria y a la agricultura, la información veraz sobre el movimiento de precios, y la educación de la mujer, del niño, el estudiante, del maestro y del campesino" 28 .

La HJN, que recibió posteriormente el nombre de Radio Nacional, trasmitía durante ocho horas diarias y su programación estaba conformada por música, noticias científicas, información general y un noticiero donde se daba específicamente información que tenía que ver con las medidas y decisiones tomadas por el gobierno ${ }^{29}$. Entre 1940 y 1948 la Radio Nacional tuvo su “Época de Oro”. Este periodo estuvo caracterizado por ser una fuerte organización radial que contaba con personal calificado, amplia nómina, y además tenía gran capacidad técnica.

El trabajo de Renán Silva muestra que la Radio Nacional fue una fuente de educación cívica al trasmitir información relacionada con las normas electorales y también al emitir programas radiales que daban a conocer la geografía del país con sus diferentes regiones. "La idea era la de favorecer el conocimiento entre las gentes de las distintas regiones respecto de su historia, de sus costumbres y su estado de progreso material" 30 .

Durante esta "etapa de oro", en general, se ampliaron y diversificaron las labores de divulgación oficial y educativa y del mismo modo se amplió el cubrimiento de la Radio Nacional en todo el territorio del país. Hacia 1944 se incorporaron nuevos 
estilos modernos de periodismo radial, como las entrevistas y las conferencias, que se habían convertido en nuevos géneros a partir de la Segunda Guerra Mundial. En general, el éxito durante estos años de la Radio Nacional se dio gracias a la participación decidida de personas que hacían parte del proyecto de la República Liberal y que además apoyaban la idea de extender y fortalecer la formación cultural. Algunos de los reconocidos hombres que participaron en esta etapa de la Radio Nacional fueron Eduardo Caballero Calderón, Hernando Téllez, Eduardo Carranza, Rafael Maya, Bernardo Romero y Jorge Zalamea, entre otros.

Para Renán Silva, existieron unos elementos que favorecieron el avance inicial de la Radio Nacional; ellos fueron, por una parte, las calidades del grupo de colaboradores y, por otra, la Segunda Guerra Mundial, puesto que "los Estados Unidos y la Gran Bretaña, potencias de la radio, intensificaron su trabajo diplomático y cultural sobre los países latinoamericanos" ${ }^{31}$, convirtiéndose en una fuente de constante apoyo en el campo técnico, en el intercambio cultural y en la implementación de nuevos géneros de producción periodística.

Sin embargo, la débil democracia colombiana, sumida en un escenario de constante violencia partidista, marcó el final del proyecto de extensión cultural con el que se fue borrando la memoria cultural del país y la posibilidad de construir una nación con identidad. Silva, en este sentido, afirma que la pérdida de esa memoria cultural no solo afectó “la memoria intelectual sino la memoria social popular, en cuanto a los elementos de nación que, muy primariamente se había tratado de construir y que buscaba un punto de enganche con la historia anterior del país"32.

A medida que perdía espacio e importancia cultural la Radio Nacional, se fueron fortaleciendo otras experiencias radiales, pero también se fue consolidando un amplio sector privado que empezó a trabajar comercialmente con este medio de comunicación. Hernando Téllez muestra en su libro Cincuenta años de la radiodifusión en Colombia ${ }^{33}$ cómo se fueron creando diferentes estaciones de radio y posteriormente grandes cadenas radiales que coparon el dial de los transistores que tenía la mayoría de las familias del país.

Para mediados de la década de 1940, la radio ya se había empezado a convertir en un instrumento indispensable en los hogares colombianos para estar informado

31. Ibid., p. 83.

32. Ibid., pp. 84 y 85

33. TÉLLEZ, Hernando. Cincuenta años de Radiodifusión en Colombia. Bogotá, Editorial Bedout S.A., 1974. 
y 'conectado' con los eventos del país: “la extensión de la cobertura y la posesión de un aparato receptor era ya un hecho en vía de generalización en el país"34, aunque el proyecto cultural de la Radio Nacional ya no fuera el objetivo principal, sino nuevas iniciativas de carácter comercial, pero también educativo, como sería el de Radio Sutatenza.

Para poner en marcha la idea de Radio Sutatenza, no solo influyó la cercanía a los medios de comunicación y la creación de nuevas iniciativas radiales en el país, sino que también fue importante la formación que tuvo Salcedo en el seminario y el apoyo constante que recibió por parte del obispo de Tunja.

La formación de Salcedo en el seminario se da en un momento de crisis social en el país y de reflexión de la Iglesia ante el avance del liberalismo y el socialismo. La preocupación de la Iglesia Católica, por una parte, se debe a la pérdida de fieles, por otra a la pérdida de influencia en diferentes esferas de la vida de los seres humanos. Durante las primeras tres décadas del siglo XX se empezaron a constituir en Latinoamérica los movimientos de acción social de la Iglesia, por medio de la Acción Católica. Esta última era un instrumento que permitía que se pusiera en marcha un sistema social para las clases más desposeídas, a partir de la colaboración y ayuda de las clases dirigentes; es decir, la Acción Católica fue el medio que pretendía despertar la conciencia social en aquellos que poseían mayores riquezas y comodidades.

La doctrina social católica tuvo sus orígenes al final del siglo XIX, cuando León XIII, quien ejerció como máximo jerarca de la Iglesia Católica entre 1878 y 1903, impulsó, con la encíclica Rerum Novarum, nuevas instituciones donde los laicos tuvieran un protagonismo activo en los temas concernientes a la educación cristiana. Rerum Novarum resalta los beneficios que dejan a la humanidad los servicios de instituciones, corporaciones, congregaciones y órdenes religiosas, pero también destaca que la Iglesia tiene plena potestad sobre ellas. Pío XI, el sucesor de León XIII, fue quien llamó a la conformación de la Acción Católica mediante la encíclica Il Fermo proposito; esta directriz del Papa reafirmaba que las obras sociales llevadas a cabo debían estar bajo la tutela del clero y de la jerarquía.

Es así como la encíclica Rerum Novarum y el surgimiento de la Acción Católica marcaron un periodo de transición de la Iglesia hacia la modernidad. Con este periodo se inicia una nueva relación con el laicado y su organización, y una concepción sobre el tema social, que no está limitado exclusivamente a la caridad,

34. SILVA, Renán. Op. cit., p. 85. 
sino también a la organización de movimientos y grupos sociales que trabajaran por el desarrollo y la mejora en las condiciones de vida de los más pobres y desposeídos. Esto a pesar de la resistencia que oponía Roma ante la amenaza de que se fortaleciera el liberalismo laicizante.

Tanto la encíclica Rerum Novarum como la conformación de la Acción Católica, empezó a ser impulsada a principios del siglo XX en Colombia; de esta manera, buena parte de jerarquía eclesiástica y párrocos empezaron a promover la organización de movimientos de laicos católicos que aportaran y colaboraran en las obras sociales que requería el país. La reivindicación de los obreros y campesinos, y el mejoramiento tanto de sus condiciones de vida como su situación laboral fue objetivo de esta empresa iniciada por la Iglesia, para así cerrarle el paso al liberalismo y al socialismo que habían acogido las necesidades de esos sectores como suyas. Lo que marcaba la diferencia es que la "lucha" del clero por esas reivindicaciones estaba acompañada por la formación cristiana. En este sentido, Ricardo Arias explica que las dos encíclicas mencionadas anteriormente “sientan las bases para el desarrollo de esa militancia católica que rápidamente se diversifica, pero que siempre pretenderá inculcar los valores cristianos en todos los niveles de la sociedad"35.

No era extraño, entonces, encontrar que en las primeras décadas del siglo XX, la Iglesia ya estuviera trabajando en la creación y consolidación de movimientos en el marco de la acción social católica. Para cumplir con lo trazado, el episcopado inició un proceso de sensibilización al clero en lo referente a los problemas sociales que aquejaron a la población colombiana, especialmente a los obreros, acompañada de lecturas de documentos papales como la encíclica Rerum Novarum. Además, se crean cátedras en los seminarios sobre acción social católica que le permitían a religiosos y estudiantes apropiarse de las "herramientas doctrinarias indispensables no solo para responder a las expectativas de las clases trabajadoras, sino también para hacer frente a los embates de la izquierda en el terreno social"36.

Junto con la instrucción necesaria para el clero, se incentiva la creación de instituciones de carácter popular que ayuden a mejorar o aliviar las dificultades de la vida de trabajadores y familiares. En este sentido, se crean cajas de ahorro, cooperativas de agricultores, bibliotecas, escuelas de arte y oficios, y bancos agrícolas, entre otros.

35. ARIAS, Ricardo. Op. cit., p. 60

36. Ibid., p. 101 


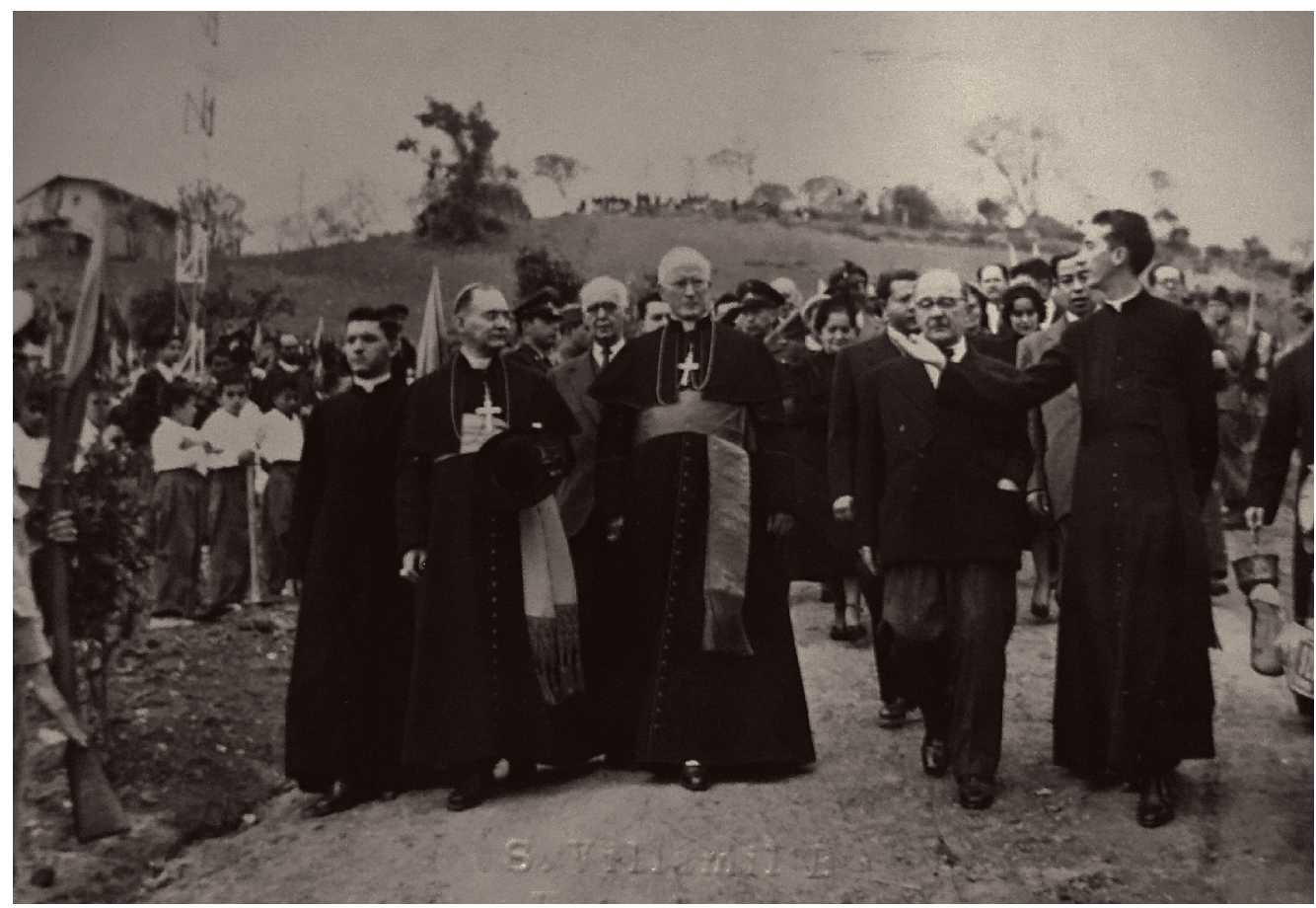

Monseñor Crisanto Luque y el Padre José Joaquín Salcedo.

Sin embargo, la transformación de la sociedad colombiana en estos primeros años necesitaba de una respuesta clara de la Iglesia, que se vio reflejada en la organización de la Acción Católica en Colombia a partir de 1933; su función consistió en lograr la colaboración de los laicos mediante organizaciones que trabajaran en la difusión de los principios cristianos y la relación de estos con la vida individual, familiar y social ${ }^{37}$.

Las acciones emprendidas por la acción social católica desde 1913 y los inicios de la Acción Católica en Colombia, con el establecimiento de sus estatutos en 1933, generaron y proyectaron el trabajo social desarrollado por la Iglesia con la participación del clero y del laicado. Por esa época surgieron varias opciones que pretendían ser una respuesta a los problemas sociales que enmarcaban la modernización. Tal fue el caso de la Juventud Obrera Católica, que organizó a obreros y campesinos en sindicatos, configurándose en una alternativa diferente a los partidos. 
El arzobispo de Tunja, monseñor Crisanto Luque Sánchez, apoyó y colaboró para que la Acción Católica en la región se extendiera y se consolidara. Durante los 18 años que ejerció la labor episcopal en la diócesis de Tunja, empezando en 1932, monseñor Luque organizó más de 150 sindicatos obreros y campesinos, y creó la Unión de Trabajadores de Boyacá (UTRABO). Además, apoyo la fundación de la Caja Popular Cooperativa, el Seminario de orientación vocacional de Tuta y participó en la creación de la Coordinación de Acción Social, donde se estableció un canal de comunicación entre la jerarquía y las clases trabajadoras ${ }^{38}$.

Es evidente que la Acción Católica no fue ajena para monseñor Luque; por el contrario, este desarrolló actividades tendientes a proyectarla en toda la región boyacense. No resulta extraña, entonces, la decisión de monseñor en apoyar proyectos que de una u otra manera estuvieran relacionados con el acercamiento a las comunidades obreras y campesinas en Boyacá. En relación con el apoyo a Salcedo, el padre jesuita Francisco Javier Mejía, en la revista Javeriana, exaltó la labor desarrollada por el Obispo de Tunja, monseñor Crisanto Luque: "Sin él esta obra no hubiera existido. Su clarividencia vio que lo que otro pudiera calificar de chifladuras de un amateur de radio, era una nueva ruta para llegar a las almas" ${ }^{39}$.

Si nos remitimos al texto del escritor y periodista colombiano Luis Zalamea, sobre la vida y obra de Salcedo ${ }^{40}$, podemos hallar referencias que muestran el constante apoyo que recibió Salcedo por parte de monseñor Luque, tanto para continuar sus estudios como para iniciar posteriormente su proyecto radial ${ }^{41}$.

La creación de nuevas instituciones en el marco de la acción social de la Iglesia incluía una serie de actividades relacionadas con la educación, como las escuelas de artes o la administración de instituciones escolares. De otra parte, no era ajeno el manejo de medios de comunicación como el periódico El Catolicismo o la Revista Javeriana como instrumentos para la divulgación del pensamiento del clero y para criticar y controvertir todo aquello que estaba en contra de los intereses de la Iglesia.

38. www.cec.org.co

39. Revista Javeriana, No. 160, noviembre de 1949.

40. ZALAMEA, Luis. El Quijote Visionario, Bogotá, Jorge Plazas Editor, 1994

41. Según el texto de Luis Zalamea, el mismo Salcedo le comenta que en varias ocasiones fue suspendido del seminario y así mismo, en varias ocasiones, monseñor Crisanto Luque abogó por él para que fuera reintegrado. Las suspensiones tenían que ver en muchos casos por obstinarse en llevar cine a los pueblos de Boyacá y proyectarlo en sus plazas, también por hacer lecturas prohibidas que tenían que ver con el comunismo. 
Desde el seminario, José Joaquín Salcedo empezó a trabajar con medios de comunicación. En las plazas de los pueblos de Boyacá proyectaba películas en $16 \mathrm{~mm}$ con un equipo sonoro de su propiedad. La acogida de la población permitió a Salcedo entender y confirmar la eficacia de los medios de comunicación para llegar a los campesinos ${ }^{42}$. La formación educativa fue el otro campo que exploró Salcedo en el seminario, una de esas experiencias se dio con la alfabetización de reclutas analfabetos en el batallón de Tunja, comandado por el entonces coronel Gustavo Rojas Pinilla. Allí Salcedo organizó y dirigió cursos para aquellos soldados que no sabían leer ni escribir.

La preocupación por los temas sociales y el conocimiento adquirido sobre el telégrafo y en general de los medios de comunicación, permitió que Salcedo fuera consolidando la idea de utilizar la tecnología como instrumento para el campesinado, especialmente aquel que no tenía acceso a las escuelas. Los recorridos de Salcedo por municipios y veredas le permitían reconocer ampliamente la precaria situación de los habitantes del departamento.

Tres años antes de la ordenación de Salcedo como sacerdote, en 1944, la Acción Católica creó una coordinación nacional encabezada por los jesuitas para controlar y coordinar todas las iniciativas enmarcadas en la misma. Sin embargo, la Acción Social seguía dependiendo de la Conferencia Episcopal. Los cambios que se dieron con la nueva coordinación se hicieron visibles en la crítica que se le hizo a la caridad tradicional y a la beneficencia, llevando a generar propuestas donde se buscara la participación de aquellas personas pobres, desposeídas y carentes de condiciones de vida digna.

Rodolfo Ramón de Roux considera que esta coordinación nacional fue importante, pues permitió que la jerarquía cambiara de mentalidad, formándose realmente en la doctrina social católica. A partir de este momento, se consideró primordial la formación del clero en los temas sociales y por ello los capacitó mediante cursos intensivos donde se enseñaba doctrina social, cooperativismo y sindicalismo. Estos cursos fueron el primer esfuerzo para que el clero saliera de un enfoque exclusivamente de beneficencia ${ }^{43}$.

42. ZALAMEA, Luis. Op. cit., p.72

43. DE ROUX, Rodolfo. "La Iglesia colombiana en el período 1930 - 1962". En: Historia general de la Iglesia Católica en América. T. VII, p. 531 
La relación de la Iglesia con sus creyentes y especialmente con comunidades como los obreros y el campesinado, se transformó debido a las circunstancias económicas, políticas y sociales del país. Los cambios en materia política, por ejemplo, llevaron a que la Iglesia tomara acciones que le permitieran adaptarse mejor a los nuevos retos; esas acciones determinaron transformaciones en los modelos del trabajo social. La Iglesia pasó a tener un sector del clero con una posición modernizante y reformista.

Juan Luis De Lannoy y Gustavo Pérez plantean un ejemplo de los cambios mencionados cuando proponen la necesidad de que la Iglesia instruya a la población para disminuir las altas tasas de natalidad. La idea era educar "la mente de los fieles con la doctrina católica, sobre la reglamentación de nacimientos, pues, se observa que el control de los nacimientos es uno de los problemas fundamentales en el alejamiento de la Iglesia" ${ }^{4}$. Existía una preocupación en este sentido, pues se consideró que la opinión de catedráticos universitarios y escritores sobre el tema estaba provocando polémicas, por eso era mejor "organizar la educación de las familias y de los médicos y enfermeras sobre los métodos lícitos de reglamentación de los nacimientos" 45 . Para la Iglesia, según los autores mencionados, era imperioso mostrar el problema del aumento demográfico como una cuestión de justicia social.

Estas acciones exigían un mayor número de sacerdotes y laicos, y nuevas formas y bases de apostolado, lo que implicaba cambios en las estructuras y en la mentalidad de los colombianos. La reconocida devoción católica de los habitantes de Sutatenza permitía que la participación del campesinado en los proyectos de la Iglesia fuera posiblemente mayor que en otras zonas del país. Fals Borda comentaba que "es de conocimiento general que el pueblo boyacense es casi en su totalidad católico romano. Esta homogeneidad religiosa es una de las principales y más influyentes características de Boyacá"46.

La religión en esta zona del país permitió que existiera un mecanismo de cohesión social, pues las creencias católicas de los habitantes permitían que se practicara la religión colectivamente en las diferentes celebraciones. Además, la percepción que se tenía de los párrocos era bastante positiva, según lo estableció la investigación Sacerdote y Cambio social ${ }^{47}$.

\footnotetext{
44. DE LANNOY, Juan y PÉREZ, Gustavo. Estructuras demográficas... p. 101.

45. Ibid.

46. FALS, Orlando. El Hombre y la Tierra... p.49.

47. JIMÉNEZ, Gustavo. Sacerdote y Cambio social, Bogotá, Tercer Mundo, 1967.
} 
Las necesidades apremiantes de la población, en una etapa donde se pedía mayor desarrollo, era también un llamado a la Iglesia para que se comprometiera

con el apoyo y favorecimiento de procesos o "factores de evolución social que conducen a una civilización técnica y urbana"48. El modelo de desarrollo propuesto hasta ese momento pasaba más por una formación técnica que vinculara al ciudadano al mundo laboral con unos conocimientos básicos que le permitieran mejorar la calidad de vida y los niveles de productividad. Es lo que posteriormente se llamó "desarrollismo". Desde esta perspectiva, la Iglesia apoyaría opciones relacionadas con reformas agrarias que le dieran valor al medio rural en aspectos como la higiene, la productividad y los niveles de vida del campesino. Igualmente, iniciaría acciones que permitieran agrupar los habitantes rurales en núcleos que facilitaran su educación y la asistencia, tanto técnica como social y religiosa.

Respecto al uso de tecnologías u otros medios tradicionales para el cultivo, Fals Borda afirma que aunque existen casos de "agricultura del fuego" 49 , en Boyacá los campesinos "ejercen su profesión todavía dentro del complejo del azadón y el arado rudimentario" 50 . En el Valle de Tenza los medios eran aún más "primitivos": el uso del azadón era escaso y primaba la utilización de la pala de cabo largo junto con el machete ${ }^{51}$.

Pérez y De Lannoy reconocieron que ACPO desarrollaba un trabajo pastoral a favor del pueblo campesino: "El fenómeno de la dispersión de la población en los campos obliga a la Iglesia a adoptar métodos nuevos de pastoral rural, como la Acción Cultural Popular y las misiones ambulantes" 52 . Si tenemos en cuenta el trabajo desarrollado por la Institución de José Joaquín Salcedo, su modelo coincidía plenamente con el planteamiento de Pérez, en cuanto a la necesidad de que la Iglesia apoyara a las instituciones que introdujeran procesos técnicos en la vida rural. En la población campesina se podría, de esta manera, practicar una “amplia pedagogía del aprendizaje técnico: preparando la formación mental para adquirir nuevas técnicas y motivaciones para el trabajo industrial" 53 .

48. DE LANNOY, Juan y PÉREZ, Gustavo. Estructuras demográficas.... 103.

49. Explica Orlando Fals Borda que la agricultura del fuego consistía en la práctica de los campesinos en la época de verano cuando cortaban el monte y dejaban que se secaran las ramas y hojas para posteriormente quemarlas. Tres días después, en el lugar de las quemas se sembraba maíz o papa. El objetivo principal de esta práctica consistía en evitar que la vegetación silvestre creciera.

50. FALS, Orlando. El Hombre y la Tierra... p.182.

51. Ibid., p.187.

52. DE LANNOY, Juan y PÉREZ, Gustavo. Estructuras demográficas... p. 103.

53. Ibid., p. 105. 
Gustavo Jiménez, en el trabajo Sacerdote y Cambio social muestra la influencia que tiene la religión en los aspectos seculares de la vida humana, en la vida local, y el papel del párroco como agente de mejoramiento económico y social, "que hace las funciones de un puente múltiple que conecta diferentes sectores del complejo social y cultural: sirve de puente entre las instituciones religiosas y seculares, entre la sociedad rural y la sociedad urbana, entre la unidad política local, formada por el municipio y el departamento o la nación, entre la parroquia y la diócesis o la iglesia universal"54. En definitiva, el objeto general de la investigación, según el mismo autor, es averiguar cuál es el papel del sacerdote como promotor del bienestar material para la comunidad campesina.

Como ya se mencionó, el sacerdote estaba en un puesto privilegiado frente al resto de la comunidad y eso le permitía tener una amplia influencia en los acontecimientos de los municipios donde estaba asignado. "Un estudio de recopilación de los padres Houtart y Pin reconoce que generalmente en América Latina el sacerdote rural ocupa un puesto de liderazgo en la comunidad; si bien se le critica su autoritarismo"55. Por tales razones, Jiménez afirma que los sacerdotes que se encuentran trabajando en áreas rurales o campesinas se constituyen en una fuerza importante para frenar o incentivar el desarrollo.

La investigación de Jiménez, al igual que la de Pérez, resalta la labor positiva que lleva a cabo Acción Cultural Popular en el desarrollo del campesinado colombiano, pero hace evidente la necesidad de la presencia del párroco como una condición para que pueda funcionar el proceso de educación rural. ${ }^{56}$ "Hay un consentimiento bastante unánime entre los especialistas de las ciencias sociales en reconocer el prestigio elevado de que goza la Iglesia y sus representantes dentro de las comunidades rurales, y en admitir la importancia potencial del sacerdote para impulsar u obstaculizar el desarrollo"57. Calcula Jiménez que para 1964 el porcentaje de católicos representaba el $98 \%$ de la población, lo que significaba en términos generales obediencia a la Iglesia y a su representante: el párroco.

Los obispos y párrocos tenían posiciones diversas frente a la vida social y política del país, pero sin duda por el papel que representaban en las comunidades rurales poseían un influjo importante en la vida pública. “En consecuencia,

\footnotetext{
54. JIMÉNEZ, Gustavo. Sacerdote y Cambio Social... p. 22

55. Ibid., p. 44

56. Ibid., p. 48

57. Ibid., p. 49
} 
la Iglesia constituye una fuerza potencial para canalizar la dinámica en marcha de las transformaciones sociales, en tal forma que tenga lugar una evolución en vez de una revolución destructiva y violenta" ${ }^{58}$. Era claro que esta posición proponía un cambio de actitud del clero para que se buscara mejorar las condiciones de vida de los colombianos, pero sobre todo para evitar la posibilidad de que se fraguara una revolución derivada de las carencias de campesinos y obreros, y alimentada con los discursos de algunos sectores liberales y de izquierda.

Este estudio cobra importancia en el marco de este documento, porque muestra cuál es la visión o imaginario que las comunidades tienen de los párrocos y porque además indaga con los mismos párrocos hasta dónde consideran ellos que debe llegar su papel con la comunidad. Para realizar la investigación, Jiménez se entrevistó con personas conocedoras del tema, visitó las sedes de las organizaciones de la Iglesia donde había programas de mejoramiento socioeconómico, se estudiaron los mecanismos de funcionamiento y se revisaron los archivos. Entre las sedes visitadas, estuvo la de Acción Cultural Popular.

La transformación sociocultural, según la mirada de Jiménez, ya estaba en marcha con las acciones que se habían desarrollado en esos últimos años. "La industrialización creciente, la mejora de carreteras y la construcción de caminos vecinales, la difusión del radio transistorizado entre los campesinos analfabetas, la labor de Acción Cultural Popular, los programas de acción comunal, etc., han sido fuerzas de gran poder para crear entre los campesinos una actitud de inconformidad con la situación presente y de anhelos de cambio"59. Con esta última afirmación, Jiménez, buscar establecer la relación entre los avances en diferentes áreas y el papel de la Iglesia para que estos se hicieran realidad.

El papel transformador de la Iglesia no siempre alcanzó progresos significativos y esto se debía, entre otras razones, a la misma organización de la Iglesia Católica y a su estructura de autoridad. Administrativamente, se dividía en diócesis gobernadas por obispos, y estas a su vez en parroquias que estaban dirigidas por el párroco. Afirma Jiménez que según esta estructura “cada obispo en su diócesis es independiente a la de los demás obispos" ${ }^{60}$, esto significa entonces que, dependiendo de los intereses del obispo y en sí, de la diócesis, el apoyo variaba de acuerdo con el tipo de obras que se realizaran.

58. Ibid., p. 96.
59. Ibid., p. 80
60. Ibid., p. 95. 
Las nuevas obras implementadas por la Iglesia dieron paso a una institución con un enfoque menos tradicional y asistencialista, pues la caridad y la beneficencia eran la característica de una actitud paternalista y conservadora, que en términos generales mantenía las condiciones de pobreza e ignorancia. Gustavo Jiménez explica que "la caridad, tal como ha sido entendida y practicada con frecuencia por gentes de la clase media y alta, es un patrón sociocultural que tiende a consolidar la rigidez de las estructuras sociales más bien que a levantar el nivel de vida de las clases pobres" ${ }^{61}$. Para el autor, una muestra del cambio de pensamiento en el clero tiene que ver con la conciencia tomada en torno a las injusticias estructurales del sistema tradicional sobre la tenencia y propiedad de la tierra. Las declaraciones emitidas por la Iglesia en torno a la necesidad de una reforma agraria hacia 1960 son muestra de que la Iglesia había entrado por la senda de la búsqueda del desarrollo y del cambio de algunas estructuras.

En Sacerdote y Cambio social, el autor describe y contextualiza el origen y el camino de Acción Cultural Popular, y trata de esta manera de demostrar cómo el cambio de la Iglesia y de sus párrocos se reflejaba en los procesos llevados a cabo por instituciones como ACPO. La formación educativa del campesino en diferentes áreas, la conformación de núcleos de estudio, la formación de líderes o la alusión y pedido constante de la reforma agraria eran pruebas de ese cambio.

Una respuesta positiva frente a los cambios sociales propuestos por los párrocos en sus comunidades se podía lograr en tanto las innovaciones que se llevaran a esas personas estuvieran en armonía con los valores y las experiencias de la comunidad. Ya había mencionado Gustavo Pérez que existían mayores posibilidades de que se acogieran nuevos aprendizajes si estos estaban relacionados con el entorno de los campesinos. Gustavo Jiménez, en relación con ACPO, reitera: “Con todo, la filial confianza que el campesino tiene en la Iglesia ha ayudado para que este incorpore en sus métodos de cultivo no pocos adelantos tecnológicos sugeridos por Acción Cultural Popular"62.

Seguramente, ACPO en su afán por dar una formación al campesinado, también aportó significativamente en el cambio del clero colombiano, moldeando el papel que el sacerdote debe cumplir en las zonas rurales. Acción Cultural Popular, mediante cursos y seminarios para sacerdotes, permitió que el clero tuviera mayor relación con los problemas del campesinado y buscara posibles soluciones.

61. Ibid., p. 99.

62. Ibid., p, 115. 
Es claro que donde han existido fuertes y estrechos lazos entre la Iglesia y la comunidad, las Escuelas Radiofónicas han funcionado mucho mejor. Pero también donde "predomina el minifundio" 63 . Sin embargo, dice Jiménez, el mérito de Acción Cultural Popular es que ha logrado introducir integrada y rápidamente cambios en las actitudes y valores de los campesinos.

De esta forma, aunque algunos sacerdotes siguieron aferrados al orden tradicional, a otros se les vio como decididos promotores del progreso material. De acuerdo con las entrevistas realizadas por Gustavo Jiménez, se determinó que existía unanimidad entre los laicos, pues el $97,3 \%$ considera que al sacerdote se le debía exigir un interés y una participación activa en las obras que contribuyeran al progreso material de la comunidad. Ese sentir manifestado entre los laicos también estaba presente entre los sacerdotes entrevistados con un $95 \%$. El resultado mayoritario de los 187 laicos y 22 párrocos entrevistados fue que los sacerdotes eran las personas potencialmente más importantes para el progreso del municipio.

Referente a las Escuelas Radiofónicas de ACPO, aunque la mayoría de los sacerdotes $(85 \%)$ mostraron un compromiso en la promoción y establecimiento de estas Escuelas, algunos párrocos afirmaron que no veían como obligatorio y fundamental apoyarlas. Sin embargo, tanto laicos como sacerdotes reconocen en estas un recurso válido para corregir las diferencias cuantitativas y cualitativas del sistema educativo del momento ${ }^{64}$.

En lo concerniente al caso de Acción Cultural Popular, según la investigación desarrollada por Jiménez, en general existe un acuerdo en que laicos y párrocos deben organizar el sistema de las escuelas radiofónicas en sus parroquias. Pero el objetivo principal sívaría, pues mientras los laicos creen que estas son un instrumento de educación general, los sacerdotes lo ven como una posibilidad para inculcar la vida religiosa y la moral en los campesinos. De acuerdo con el papel que deberían cumplir, los sacerdotes deberían ser protagonistas también en las reuniones que realizan las Escuelas Radiofónicas y en la promoción del periódico El Campesino.

El estudio de Jiménez muestra que los sacerdotes tienen posiciones más democráticas frente a la posibilidad de dar mayores responsabilidades al

63. Ibid., p, 117.

64. De acuerdo con las entrevistas realizadas, el autor analiza cuál es la posición de los diferentes actores sociales sobre las Escuelas Radiofónicas. Aunque reconoce que algunos no conocen de cerca la obra, también muestra que en general nadie está en desacuerdo con que se lleve a cabo. Por el contrario, una buena parte de los párrocos la aprecian y la apoyan. 
campesinado. Esto significaba que la formación que se les diera en aspectos diferentes a los agrícolas les permitía tomar autónomamente decisiones sobre el futuro de sus propias vidas.

Concluye Jiménez que, de acuerdo con las características y condiciones socioculturales existentes, se ve un sacerdote de la Iglesia Católica jugando un "papel importante como agente de cambio social y de desarrollo económico" 65 . En el caso de Acción Cultural Popular, esas condiciones, entre otras, tenían que ver con la voluntad del párroco por consagrar su tiempo y energías a esa obra, y el grado de vínculo de la comunidad con la Iglesia Católica. Afirma Jiménez que particularmente se pudo evidenciar que en las regiones donde existían los minifundios, como era la del Valle de Tenza, habían tenido mayor éxito los programas de ACPO. En relación con esta última idea, el autor dice que la propiedad de la tierra está relacionada con "actitudes mentales y emocionales que hacen al propietario más receptivo a la idea de que él es el dueño del progreso personal"66.

Un balance general de la investigación muestra que los roles de los sacerdotes con los fieles iban mucho más allá de la relación exclusivamente espiritual. El sacerdote debía estar más involucrado con la consecución de recursos, la realización de gestiones y la implementación de proyectos que beneficiaran a las comunidades. Sin embargo, las apremiantes necesidades llevaban a que en ocasiones las soluciones se proyectaran a corto plazo, evitando los cambios estructurales necesarios para mejorar la situación del campesinado colombiano.

El proyecto de Salcedo, que estaba a poco tiempo de empezar, estaría más enfocado hacia un trabajo realizado conjuntamente con el campesinado y no propiamente a un trabajo de beneficencia y de carácter asistencialista.

Las circunstancias que rodearon los años previos al origen de Radio Sutatenza fueron entonces importantes para que el proyecto radial contara con unas características muy propias de la Acción Católica. En este sentido, se debía formar núcleos de personas que estuvieran sometidos al cura en la parroquia y al obispo en la diócesis. La intención era que un grupo de apóstoles ayudaran a la jerarquía a "conquistar las almas, perfeccionarlas y hacerlas trabajar en la restauración cristiana de las familias y de la sociedad" 67 .

65. JIMÉNEZ, Gustavo. Sacerdote y Cambio social... p, 285

66. Ibid., p.264

67. BIDEGAIN, Ana. Op. cit., p.61 


\section{Inicios de Radio Sutatenza y ACPO}

Los primeros años de Sutatenza y de Acción Cultural Popular se reconstruyen a partir del relato escrito por el periodista Indalecio Rodríguez Sánchez, y publicado en el texto Educación Fundamental Integral: Teoría y aplicación en el caso ACPO ${ }^{68}$. La versión escrita por este periodista en 1978 se convirtió en la historia oficial de los orígenes de dicha obra. Esta historia oficial y la carencia de otros documentos que la verifiquen constituyen un problema para el autor de este documento, pues la verificación de la información no se puede realizar. En los archivos de Radio Sutatenza no se encuentran otros documentos que puedan evidenciar los primeros años de la obra de José Joaquín Salcedo.

Comenta Indalecio Rodríguez que el campesinado de Boyacá tenía ingresos que escasamente alcanzaban para la subsistencia, y que los habitantes de la zona del Valle de Tenza, lugar donde estaba ubicado el municipio de Sutatenza, no tenían fácil acceso a las escuelas. Sin embargo, no evidencia la situación de violencia y confrontación partidista que se vivía no solo en la región sino en buena parte del país.

\section{La violencia en Boyacá}

Los años precedentes a la creación de Radio Sutatenza estuvieron enmarcados en un contexto de violencia que recorrió todo el país. Boyacá fue, junto con el departamento de Santander y del Norte de Santander, escenario de continuas confrontaciones partidistas. Liberales y conservadores fueron actores de hechos violentos; el clero tuvo una participación importante al aliarse con el partido conservador que era la colectividad que representaba con mayor fidelidad sus intereses.

La violencia generada a partir de las guerras civiles que tuvieron lugar en el siglo XIX se mantuvo en los inicios del siglo XX. Mientras algunas regiones dentro de dichos procesos tuvieron cambios significativos y empezaron a dar pasos hacia la modernidad, otras se mantuvieron con niveles de atraso que no permitieron obtener mejores condiciones de vida. Ese fue el caso de Boyacá, que mantuvo una economía basada en la agricultura, pero con bajos niveles de tecnificación.

68. RODRÍGUEZ, Indalecio. “ACPO: origen y nacimiento”, En: BERNAL, Hernando. Educación Fundamental Integral, teoría y aplicación, Bogotá, ACPO, 1978. pp. 31- 52 
Las dificultades económicas estuvieron acompañadas de las confrontaciones partidistas y de fuertes controversias morales, que llevaron a que se mantuviera lo que Javier Guerrerollamóla “PrimeraViolencia"69, que comprendió desde la Guerra de los Mil Días hasta 1948. En este periodo se pasó de "una violencia de discurso, una violencia simbólica, imbuida de un carácter moral"70, a una violencia política en la que el clero y en general la religión católica tuvieron un fuerte protagonismo. En el caso específico de Boyacá, en sus zonas minifundistas la violencia se presentaba por la "identidad veredal y local, que se refleja en las venganzas de sangre, en los desquites de la localidad contra los desmanes cometidos por el adversario"71.

En el departamento de Boyacá, la Iglesia se constituía como un poder con amplia autonomía, que tenía una fuerte influencia en la población construida a la "luz del papel histórico de la Iglesia en la formación de la nacionalidad colombiana"72. La posición frente a la función que debía tener la Iglesia en el Estado marcó las diferencias de las doctrinas políticas, y por supuesto fue uno de los factores que determinaron la ya mencionada alianza entre el partido conservador y la Iglesia.

Esta alianza cobró un significado especial, puesto que la Iglesia con sus parroquias tuvo funciones que le daban la capacidad de controlar la actividad cultural, la educación y el accionar social e individual de la población. Esta institución, por medio de sus párrocos, tenía unos niveles de convocatoria más altos que los de cualquier otro organismo. Es decir, afirma Guerrero, "la parroquia ha sido un organismo político, administrativo..." ${ }^{73}$.

La filiación política de buena parte de la población del país estuvo enmarcada en la estrecha relación Iglesia - Estado, y por supuesto Boyacá no fue la excepción. Por el contrario, la fuerte presencia del clero en la región, sumada a las características de la tenencia de la tierra y al tradicionalismo del campesino boyacense, llevó a que este sector tuviera una filiación política mayoritariamente conservadora.

El papel de la Iglesia en las primeras décadas del siglo XX no detuvo la violencia, sino que en varios casos la propició o al menos fue fuente de agitación

69. GUERRERO, Javier. Los años del olvido, Bogotá, Tercer Mundo Editores, 1991. p. 53

70. Ibid., p. 53

71. GONZÁLEZ, Fernán. "Poblamiento y conflicto social en la historia colombiana", en Para leer la política. Bogotá, Cinep. 1997, p. 87 y 88.

72. Ibid., p. 63

73. Ibid., p. 62 
partidista que estuvo acompañada de conflictos agrarios, laborales y sociales, especialmente a partir de la crisis económica mundial de 1929. Por el escaso margen de maniobra institucional, estos conflictos fueron reprimidos con excesiva fuerza y de manera autoritaria, llevando a agudizar las confrontaciones políticas en el país.

La impopularidad del régimen conservador que llevaba en el poder 46 años, el desencanto por las secuelas del empobrecimiento del sector agrario, la corrupción y el desempleo, fueron para 1930 hechos que cobraron importancia en las campañas electorales, entre ellas la presidencial. Ese año el país presenció la caída del conservatismo y el triunfo del liberal Enrique Olaya Herrera, quien alcanzó la presidencia de la República. En este sentido afirma Javier Guerrero que realmente "el Partido Liberal no asciende por un proceso político en el que derrota al Partido Conservador, sino que más bien es el derrumbe paulatino de un régimen ahogado en sus propios problemas y debilitado en su interior por sus propias contradicciones, donde la consecuencia lógica no era otra que el relevo político"74.

Pero la transición hacia la República liberal no fue pacífica. Estuvo acompañada de fuertes tensiones a raíz de los constantes enfrentamientos con una clase política conservadora que se había enquistado en amplios sectores burocráticos del país, y que, además, aún mantenía el poder sobre varias instituciones del Estado. En Boyacá los conservadores mantuvieron el manejo de la educación, los telefonistas y la guardia departamental y municipal, lo que significa tener una "fuerza de choque partidista", que fue usada en no pocas ocasiones contra los liberales. A partir del ascenso al poder de los liberales, asegura Guerrero, la situación que se presentó en Boyacá, Santander y Norte de Santander fue calificada como "una guerra civil regional”75.

La defensa de parte del conservatismo estuvo enfocada en mantener a su favor los espacios de poder ganados durante la hegemonía conservadora, mientras que para los liberales fue imperioso conquistar esos espacios y buscar escenarios que les permitiera cambiar las tendencias electorales. Una de las medidas aplicadas fue el nombramiento de alcaldes liberales en poblaciones conservadoras; sin embargo, esa medida generó que en varias zonas se crearan fuerzas de policía cívica para que protegieran a los mandatarios locales contra los abusos de la policía departamental.

74. Ibid., p. 113

75. Ibid., p. 121 
Guerrero evidencia cómo de lado y lado fueron constantes las agresiones, las amenazas y las acusaciones sobre la participación en los hechos de violencia que repetidamente se presentaban en diferentes zonas del país. Los enfrentamientos se dieron en variados escenarios; el control que mantuvo el conservatismo en la rama judicial llevó a confrontaciones entre las instituciones encargadas de impartir justicia y la autoridad del alcalde y la policía. Es decir, lo que se presentó fue un fraccionamiento del poder del Estado, o como lo denomina Guerrero, una “desarticulación del sistema institucional"76.

Durante esta etapa, al igual que en buena parte de la vida republicana del país, el clero mantuvo una actitud de rechazo hacia las ideas liberales. Por eso, a través de los púlpitos incitó a la población creyente a que rechazara y desalojara a los liberales. Este tipo de actitudes de algunos párrocos de la Iglesia Católica, unido a otras causas generadoras de violencia mencionadas anteriormente, llevó a que el gobierno liberal intentara aplicar un proceso de pacificación que consistió en el desarme de la población, en la disolución de los cuerpos de la policía departamental y municipal, y por supuesto, en la limitación a la Iglesia en cuanto a su participación en política, además de evitar que el clero siguiera llevando a cabo actos de agitación y protección de grupos armados afines al conservatismo.

La guerra con el Perú logró frenar el clima de violencia que se presentaba en el país. Las preocupaciones delos colombianosinmersosenlaguerrasetrasladaronalafrontera con el vecino, apaciguando el debate político interno. Sin embargo, después de acabada la guerra en 1933, el partido conservador salió fortalecido "en la medida en que lo acercó más a una estrategia militar", ${ }^{77}$ hasta llegar al punto de crear escuadrones que tenían el nombre de sus más connotados líderes como Laureano Gómez. Con la finalización de la guerra, de nuevo arreciaron los enfrentamientos internos y el país se sumió una vez más en hechos violentos. En general, el proceso de pacificación llevado a cabo había fracasado.

La confrontación política se mantendría durante los años posteriores a la década de los 30 y se agudizaría el debate en torno a ambos partidos, por la llegada al poder del presidente Alfonso López Pumarejo, quien inició un proyecto político llamado la "Revolución en Marcha", que tuvo como fin crear un estado laico, en el que por medio de una reforma educativa y una reforma del concordato, la Iglesia tuviera una menor injerencia en aspectos políticos, educativos y culturales del país.

76. $\quad$ Ibid., p. 62

77. Ibid., p. 187 
Para el año de 1947, cuando Salcedo llega al municipio de Sutatenza, El Tiempo, periódico liberal, registraba constantemente los enfrentamientos entre conservadores y liberales. El presidente Mariano Ospina Pérez intentaba, con la política de Unidad Nacional, apaciguar la violencia y trabajar en colaboración con los líderes tanto del partido liberal como del partido conservador. Aún así, la violencia seguía muy presente en las zonas alejadas de la capital del país.

Los liberales se quejaban constantemente de los atropellos cometidos por los conservadores. Los dirigentes regionales del departamento de Boyacá recibían constantemente críticas por la actitud permisible ante los desmanes de los conservadores o porque ellos mismos se encargaban de ocasionarlos.

En agosto de 1947, El Tiempo denunciaba cómo en Chiquinquirá la situación de los liberales era grave, debido a la actitud agresiva de los policías:

Entre tanto, la situación en el departamento de Boyacá continúa siendo en extremo grave, como consecuencia de la actitud de algunos funcionarios del departamento y de la policía y los resguardos que, bajo la mirada indiferente del gobierno se han entregado a la empresa de sembrar el terror en la mayoría de los municipios del norte y del occidente del departamento...

Informaciones de fuente responsable en el día de ayer, indican que la formación actual de la policía de Boyacá obedece a un claro sentimiento sectario, pues del cuerpo han sido desplazados todos los agentes de filiación liberal, para ser reemplazados por conocidos y peligrosos elementos conservadores, dispuestos a todo con tal de ver afianzado a su partido en el poder... ${ }^{78}$

Las constantes alusiones a la situación del departamento de Boyacá en el periódico El Tiempo dejaban ver la difícil situación que se presentaba entre los partidarios de liberales y conservadores. Dos días más tarde, en primera página, el mismo periódico titulaba “El Directorio Liberal de Boyacá informa a los parlamentarios sobre el difícil momento actual"79, refiriéndose a las constantes muertes que se habían dado no solo en Chiquinquirá, sino también Tunja.

78. El Tiempo, 7 de agosto de 1947

79. El Tiempo, 9 de agosto de 1947 
Las ediciones de los días posteriores del mismo periódico continuaban mostrando una situación caótica de violencia en el departamento. Era el tema a tratar en las editoriales ${ }^{80}$, pues revestía gran importancia para la dirigencia liberal. Debido a las muertes sucedidas no solo en Boyacá, sino en otros departamentos como Santander y ante un eventual rompimiento de la política de Unidad Nacional del gobierno, este se ve en la obligación de llegar a un acuerdo para intentar controlar la situación en las regiones donde la violencia había hecho mayor presencia. Jorge Eliécer Gaitán, jefe del Partido Liberal para ese momento, Laureano Gómez, como jefe del conservatismo, y el ministro de gobierno, Roberto Urdaneta, acordaron entonces unas normas que permitieran mantener la unidad nacional. Entre ellas estaban el desarme, la condena de la violencia, y la caída de algunos gobernantes que habían patrocinado la violencia ${ }^{81}$. La Revista Javeriana también hizo alusión a los acuerdos, destacando la necesidad de alcanzar un "ambiente de serenidad y comprensión entre los diferentes grupos políticos del país, agitados en los últimos meses por el insano estímulo de las pasiones banderizas y el empeño contra una nueva concepción administrativa que tiende a la sana emulación entre los partidos para el mejor servicio de la república, como lo ha proclamado insistente y diáfanamente el actual mandatario" 82 .

En Boyacá siguieron presentándose hechos violentos con matices partidistas. Un ejemplo de ello, que tuvo cercana relación con el Padre José Joaquín Salcedo, fue el intento de agresión a la población de Sutatenza por parte de los pobladores liberales de Guateque, a raíz del asesinato del líder liberal Jorge Eliécer Gaitán en Bogotá, pues la Iglesia aún conservaba esa imagen de ser una institución aliada al partido conservador. Luis Zalamea, escritor, periodista colombiano y amigo de Salcedo, narra este capítulo de cómo la violencia también llegó hasta las puertas de Sutatenza:

La situación se tornó muy peligrosa para el Padre Salcedo. Llegaron a sus oídos rumores de que los liberales, que eran mayoría en Guateque, consideraban que había que eliminar a Radio Sutatenza por 'goda y gobiernista'. En efecto, organizaron una cabalgata para tomarse la emisora y aprehender a su director. Para ello lo primero que hicieron fue cortar la luz pública del pueblo, pero el padrecito reaccionó como veterano estratega. Primero prendió su propia planta eléctrica a la 1 a.m. e hizo sonar los altoparlantes a todo volumen mientras que sus ayudantes, según lo previamente acordado, soltaban una salva de voladores. ${ }^{83}$

\footnotetext{
80. El Tiempo, 10 de agosto de 1947

81. El Tiempo, 24 de agosto de 1947

82. Revista Javeriana, No. 139, octubre - noviembre de 1947

83. ZALAMEA, Luis. Un Quijote Visionario. Bogotá, Jorge Plazas S. Editor. 1994. p.111
} 
Según Zalamea, la idea era que creyeran que era fuego de armas y así evitar la entrada al pueblo de los habitantes de Guateque, único pueblo liberal alrededor del Valle de Tenza. Para Salcedo, este fue el único acto político de su vida, aunque arguye que se trató realmente de una defensa. ${ }^{84}$

Con la muerte de Jorge Eliécer Gaitán se inició otro periodo de la violencia en el país que está comprendido entre 1949 y 1953, según Jesús Antonio Bejarano. La violencia se trasladó al campo, lugar donde se encontraban posicionados los partidos. Esta etapa, dice Bejarano, tiene dos subfases, una que estaba determinada por una lucha por la hegemonía del poder político, y otra, que fue el ingreso del Partido Comunista al escenario político en diferentes regiones del país. ${ }^{85}$

\section{Transmite Radio Sutatenza}

Bajo las tensiones políticas mencionadas empezó labores en el municipio de Sutatenza el sacerdote, recién ordenado, José Joaquín Salcedo. Había llegado el 23 de agosto de 1947 a colaborar como párroco coadjutor del padre Eliécer Pinto, en una población que contaba con 8.000 habitantes en total, la mayor parte de ellos minifundistas y asentados en el sector rural. Los índices de analfabetismo superaban el 85 por ciento de la población. El trabajo de Indalecio Rodríguez comenta cómo Sutatenza se caracterizaba también por ser una población donde se consumía en exceso la chicha, ocasionando permanentes peleas y discusiones entre los habitantes, lo que ocasionaba por lo general muertos y lesionados ${ }^{86}$.

El difícil acceso a las escuelas y el bajo porcentaje de alfabetización se convirtió en el escenario propicio para desarrollar procesos educativos con la ayuda de medios tecnológicos como la radio. Salcedo realizó el montaje de la primera radio escuela a los pocos meses de su arribo a Sutatenza. Un equipo de radioaficionado y tres receptores sirvieron para dictar unas clases de catecismo. La primera obra que realizó de manera conjunta con la población fue la construcción de un teatro

84. A partir de la entrevista realizada por Zalamea para escribir el libro Un Quijote Visionario, José Joaquín Salcedo explica el papel que tuvo en el levantamiento de los habitantes de Guateque en contra de Sutatenza y, según él, en contra de Radio Sutatenza. Para Zalamea, a partir del 9 de abril de 1948 la violencia política se recrudeció en todo el país, y especialmente azotó los pueblos y las veredas.

85. BEJARANO, Jesús. “Campesinado, Luchas Agrarias e Historia Social”, en Anuario Colombiano de Historia Social y de la Cultura. Volumen 11. Bogotá, Colombia.

86. RODRÍGUEZ, Indalecio. “Acpo: Origen y nacimiento” Op cit. pp. 31- 52 
donde pudieran ver cómodamente las películas que ya se habían empezado a proyectar. Para realizar esta obra, los campesinos hicieron donaciones de huevos, gallinas y productos del campo, además de su trabajo ${ }^{87}$.

El padre Salcedo, desde los primeros días que llegó a Sutatenza, inició labores para conseguir un equipo de radioaficionado. Con la ayuda de su hermano Antonio, diseñaron el transmisor. De la misma manera, adelantó las gestiones para adquirir en Bogotá el radio-receptor. Como el abastecimiento de energía era muy esporádico, se consiguió una planta eléctrica que permitió mantener durante mayor tiempo el suministro de energía necesario para el adecuado funcionamiento, tanto de los equipos de radiodifusión como de los aparatos necesarios para la proyección de películas. Una sábana blanca y un proyector lograban que las plazas de los pueblos se convirtieran en un teatro.

La fecha oficial de la primera transmisión radial fue el 16 de noviembre de 1947, dirigida a una vereda cercana llamada Irzón. Allí los labriegos ya tenían un radio-receptor que operaba con pilas. La trasmisión inició con unas palabras de saludo y continuó con una pieza musical. De esta manera se inició el trabajo de una de las experiencias más importante de educación campesina en Colombia.

Mientras se iniciaba el proyecto de Radio Sutatenza, otras obras sociales se desarrollaban en diferentes lugares del país y con fines diversos. El periódico El Catolicismo promocionaba constantemente en sus páginas las labores desarrolladas por la Acción Católica, considerándola como:

...el elemento más dinámico y poderoso para el implantamiento de la vida cristiana de que dispone la Iglesia Católica. Son sus funciones tan diversificadas que en ellas se atienden a todos los sectores de la actividad espiritual y material humanas, e incluye y alcanza en su organización todas las esferas sociales, desde aquellas de más alto rango hasta las más sencillas y humildes, en un espíritu de unión y fraternidad que eliminan las barreras que distancian a los seres humanos... ${ }^{88}$

87. "El teatro contaba con 38 metros de largo y once de luz, planeado con todos los requisitos que hoy se estilan en el arte escénico. Sus cimientos de 2 metros de profundidad y 1,20 de ancho desafían la incuria e inclemencias del campo. Allí, los campesinos de Sutatenza han ofrendado, además de aportes en dinero (se llevan gastados unos veinte mil pesos), la reciedumbre de sus músculos y la habilidad práctica de sus mentes en un trabajo gratuito". En: Revista Javeriana, No. 160, noviembre de 1949.

88. El Catolicismo, 11 de diciembre de 1949. 
Igualmente, bajo estas mismas directrices, Salcedo hizo el llamado a los habitantes de Sutatenza, para que unidos y en fraternidad buscarán objetivos comunes que les ayudaran a superar las dificultades y carencias, tanto en lo material como en lo espiritual. De esta manera, Salcedo integraba a la población a las soluciones y la invitaba a participar activamente de ellas. "Yo no puedo hacerlo solo. El mejoramiento tenemos que hacerlo juntos" ${ }^{89}$, decía.

Todos los grupos, asociaciones y acciones sociales debían estar bajo la supervisión de las jerarquías. El Catolicismo, por medio de un artículo, hizo énfasis en ese sentido refiriéndose a los cuatro puntos expuestos como norma por el Papa Pío XII. El primero, tenía que ver con la estrecha relación que debía existir entre los obispos, la jerarquía y la Acción Católica; el segundo, el estudio del catecismo y la permanente oración; la tercera, la permanente unidad entre los miembros de la Acción Católica, y la cuarta, la armonía con las otras obras; así se hubieran creado antes de la Acción Católica, hacían parte de ella por orden del episcopado ${ }^{90}$.

Pero la Acción Católica también tocaba otros terrenos más allá de los exclusivamente evangelizadores. Durante el discurso del Papa a las mujeres de la Acción Católica italiana, hizo énfasis en la necesidad de conseguir avances en la justicia social, entendida como mejor acceso a la educación y la consecución de viviendas dignas ${ }^{91}$.

El Catolicismo hizo eco constante para que se continuara con asociaciones que llevaran al crecimiento y proyección de la Acción Católica en Colombia. En sus páginas difundió los grupos que venían trabajando en diferentes lugares y zonas del país, como en Cartagena.

Radio Sutatenza no fue entonces una obra aislada en un pequeño pueblo de Boyacá, sino que respondió a la actividad que venía desarrollando la Iglesia Católica en relación con los temas sociales y con la necesidad de acercar a las personas a las obras de la Iglesia para la búsqueda del bienestar individual y del prójimo.

En ese contexto se originó Radio Sutatenza, como una opción para la educación de los campesinos y como un medio para la evangelización. El uso de la radiodifusión ya había empezado años atrás (1930), pero aún eran muy pocas las emisoras que

89. RODRÍGUEZ, Indalecio. “Acpo: Origen y nacimiento” Op cit. p. 39

90. El Catolicismo, 25 de diciembre de 1949. p.10

91. El Catolicismo, 26 de febrero de 1950. p.9 
funcionaban en el país. Estaba en el dial la Radiodifusora Nacional, que era de carácter oficial, la HKF y la Voz de Antioquia, entre otras.

Si bien el proyecto de Radio Sutatenza inició labores con la construcción del primer transmisor y puesta en funcionamiento en 1947, se constituyó como organización el 18 de octubre de 1949, cuando obtuvo la personería jurídica civil mediante resolución 260 del Ministerio de Justicia, y bajo el nombre de Acción Cultural Popular. Un mes atrás, exactamente el 6 de septiembre de 1949, se inauguraron oficialmente las Escuelas Radiofónicas por parte del Gobierno Nacional. Ese día el presidente de la República, Mariano Ospina Pérez, dirigió una alocución a los campesinos de Colombia en la que destacaba la necesidad de que por medio de las Escuelas Radiofónicas se integraran los conocimientos en diversas áreas y la formación religiosa: "La instrucción moral y religiosa, la historia patria, los conocimientos de agricultura e higiene combinados con las lecciones para aprender a leer y a escribir, hacen que sobre los campos, en la penumbra de la tarde, empiece el amanecer de las inteligencias..." 92

Escasamente llevaba dos años de iniciada la labor de Radio Sutatenza y ya alcanzaba una notoriedad a nivel nacional, por una parte, como se mencionó, el presidente de la República asistió al acto de constitución de ACPO y, por otra, se hacía ya mención en los medios de comunicación como la Revista Javeriana y El Tiempo al trabajo realizado por las radio- escuelas a la cabeza del padre Salcedo.

Las Escuelas Radiofónicas se empezaron a presentar como la solución a los problemas del campesinado colombiano y como la fórmula que permitía el acceso del campesinado a la educación. El padre Francisco Javier Mejía, en un artículo titulado "Las Escuelas Radiofónicas”, mostraba las adversas condiciones del campesinado al que le negaban la posibilidad de educarse, pero destacaba la labor que venía desarrollando Salcedo como el método indicado para acabar con la ignorancia de esa población:

Pensar en la educación del campesino es una ciega quimera: las enormes distancias, los fatigantes senderos por los repechos y cañadas, el cavernario aislamiento de nuestros campesinos, su indolencia ingénita, el estrecho horizonte de sus aspiraciones, su racial desconfianza y mil causas más levantan una muralla china que

92. El Campesino, Bogotá, 27 de noviembre de 1988. p.9 
circunda de ignorancia a nuestro pueblo... pero ¿cómo realizarla? En el mismo campo, imposible... Una campaña entre campesinos hay que encuadrarla en la paradoja de un día con duración de una semana. Pero un joven y dinámico sacerdote del clero boyacense ha encontrado la fórmula... ${ }^{93}$

De esta manera, de una parte, Mejía mostraba cómo las clases dirigentes poco hacían por una población que era mayoritaria en el país, pero también que la misma clase campesina tenía unas características que no le permitían acceder fácilmente a la educación. Se daba por hecho que el campesino estaba resignado a su suerte $y$, por lo tanto, difícilmente deseaba mejorar sus condiciones de vida.

Sin embargo, el texto del padre jesuita, por ser uno de los pocos documentos que dejaron huella de los primeros años de Sutatenza, cobra importancia. Allí describe a las Escuelas Radiofónicas técnicamente como la Emisora Cultural del Valle de Tenza HJKI, de onda larga, con 1.580 kilociclos y con una potencia de 300 watios, lo suficiente para cubrir aproximadamente 60 kilómetros a la redonda. Para el año de 1949 ya se había ampliado el número de equipos. Se contaba con la emisora, los transmisores, los preamplificadores, micrófonos, antenas, tocadiscos, discoteca y planta eléctrica, infraestructura que tenía un valor aproximado de 15.000 pesos, alcanzados en su mayoría mediante las donaciones realizadas por los mismos campesinos. Del mismo modo, Mejía hace alusión a los receptores que tenían un costo de 121 pesos y funcionaban en cada una de las escuelas. Estos aparatos estaban previamente sincronizados para que funcionaran exclusivamente en la frecuencia de Radio Sutatenza.

Con solo dos años de funcionamiento de la emisora, y a pocos días de la inauguración oficial de las Escuelas Radiofónicas, ya se contaba con 90 escuelas y con 7.000 alumnos que habitaban las veredas de los municipios de Sutatenza, Guateque, Tenza, Pachavita, Macanal, Garagoa, Almeida, Somondoco, Guayatá y Manta94.

Durante los primeros años, los profesores fueron el padre José Joaquín Salcedo junto con el maestro Enrique Parra, quien recibía un pago del departamento de Boyacá. Sin embargo, ya se trabajaba con un maestro auxiliar, que era un campesino

93 Revista Javeriana, No. 160, noviembre de 1949 pp. 285 - 286

$94 \quad$ Ibid, pp. $285-286$ 
dotado de algunos conocimientos en escritura y lectura, para así colaborarles a los otros campesinos en la comprensión de las explicaciones dadas mediante la radio. Este trabajo estaba guiado en su totalidad desde la emisora por el maestro principal.

Fundamental, los objetivos iniciales del proyecto abarcaban la enseñanza de asignaturas básicas como la lectura y la escritura, con el ánimo de atacar el grave problema del analfabetismo entre el campesinado; y de algunas nociones en historia patria, agricultura, higiene, música, urbanidad, cívica y religión. Por medio de estas nociones se abarcaban otros ámbitos de la vida del campesinado que tenían que ver con la recreación, la familia y su trabajo en el campo.

La visita de Mariano Ospina Pérez, por supuesto, mostraba ya un apoyo por parte del gobierno nacional, que pasó del discurso del presidente a la notable colaboración del Ministerio de Educación Nacional, el cual donó las cartillas que servían de guía de estudio a los campesinos y eran distribuidas por Acción Cultural Popular en cada nueva escuela radiofónica. De la misma manera, el ministro de Higiene apoyó a ACPO en su objetivo de disminuir el consumo de chicha entre los pobladores de la zona.

La proyección de las primeras películas en la plaza de Sutatenza le dieron un carácter cultural al trabajo que empezó a desarrollar José Joaquín salcedo desde 1947; no obstante, la inclusión de la radio como un instrumento divulgador de conocimientos básicos permitió crear un modelo educativo que disminuyera el analfabetismo en la zona del Valle de Tenza, en el departamento de Boyacá y posteriormente en las diferentes regiones del país.

Este proyecto educativo, como ya se mencionó, estaba acompañado de otros aprendizajes que replicaban las asignaturas que se daban en las diferentes escuelas del país, aprendizajes que reforzaban imaginarios relacionados con la historia, el civismo y el Estado, además de las enseñanzas de los principios cristianos católicos. En fin, por medio de la enseñanza se encontraba el fin mismo del proyecto de Acción Cultural Popular.

En ese sentido, el objetivo específico de ACPO quedó establecido en el artículo 3 de los estatutos aprobados por la Resolución 260, y afirma que “Acción Cultural Popular tiene por fin la educación integral cristiana del pueblo, especialmente de los campesinos adultos, mediante las Escuelas Radiofónicas". 
Para ACPO, la educación integral se entendía como la formación y enseñanza en diferentes campos de la vida humana, campos que no solo estaban relacionados con el ser humano como individuo, sino también con la relación de este con la sociedad. La Iglesia, de esta manera, abarcaba un escenario de influencia bastante amplio y lograba que las enseñanzas dadas en las diferentes áreas estuvieran relacionadas con su doctrina. 